\title{
Optimal power flow using multi-objective genetic algorithm to minimize generation emission and operational cost in micro-grid
}

\author{
Ontoseno Penangsang, Primaditya Sulistijono ${ }^{*}$, Suyanto \\ Institut Teknologi Sepuluh Nopember, Jl. Arief Rahman Hakim-Kampus Keputih-Sukolilo, Surabaya and 60111, Indonesia
}

\begin{abstract}
This paper proposes an optimal power flow (OPF) method that considers the entire system to determine the optimal operating strategy and cost optimization scheme as well as the reduction of emissions for micro-grid. Recent works emphasize optimal operation to minimize cost and emission without considering the OPF. This work applies optimal power flow solution including constrains in micro-grid system. The OPF process utilizes multi-objective genetic algorithm optimization. The method is programmed in MATLAB and tested on a modified IEEE thirty-bus test power system which has distributed generation integration. The results are compared with optimization without OPF. Based on these results, the optimization with OPF will determine optimal solution close to real condition as well as safety of the system.
\end{abstract}

Keywords: Genetic algorithm, micro-grid, multi-objective, optimal power flow (OPF)

\section{Introduction}

The current electrical power needs are increasing rapidly in line with technological developments. This electrical power needs increase in contrast with depletion of the energy sources availability of oil and coal. This problem has an impact on the national power resistance. As a good supplementary form for large power supply and large-scale energy base, distributed generation system increasingly becomes an important way to meet the needs of load growth, reduce pollution, increase energy utilization efficiency, improve supply reliability and so on [1]-[3]. The sources of distributed generation are renewable energies in order to minimize the use of energy sources of oil and coal. The distributed generation is integrated into the main grid through intelligent micro-grid. With more distributed generation integrated into grid, it is important to determine the optimal electrical power generation from each distributed generation so that the electrical power needs can be met with minimal operational cost and emissions [3].

OPF is an important tool for power system operators both in planning and operating stages. OPF can be used to perform optimal scheduling generation in the inter-connected power system. The main task is to adjust some control variables (e.g. active power generation from power plants, generator terminal voltage, reactive power compensation and on-load tap changers of transformers) in a power system, so that the best operating point can be achieved. With regard to 'best', it means this operating point can minimize or maximize certain objective function (e.g. active power loss in the target system or social welfare from the target system) while satisfying certain constraints (e.g. bus voltage magnitude limits and generation limits) [4]-[6].

In previous research, economic-emission dispatch of micro-grid system is applied without considering transmission and voltage constraints [7]. Different from previous research, the proposed approach applies OPF using multi-objective genetic algorithm to minimize emission and operational cost in micro-grid

\footnotetext{
* Manuscript received May 14, 2014; revised July 16, 2014.

Corresponding author: Primaditya Sulistijono; Tel.: +62 811327110; E-mail address: prima_didit@yahoo.com

doi: $10.12720 /$ sgce.3.4.410-416
} 
system. OPF is integrated in the economic-emission dispatch based on artificial intelligence by using multi-objective genetic algorithm. This algorithm is applied to find the optimal solution which is a compromise between multiple and contradicting objectives, which determines an optimal power flow solution that considers the system limitations such as voltage and power limits.

\section{Illustrative Micro-Grid Model}

Typical micro-grid is shown in Fig. 1. The model tested in this research is shown in Fig. 2. It combines many electrical sources on a plant. These electrical sources are wind turbine (WT), micro turbine (MT), diesel generators (DG), photovoltaic arrays (PV), fuel cells (FC). Many of them are renewable energy sources like WT and PV so the fuel input is needed only for the DG, FC, and MT. To serve the load demand, electrical power can be produced either directly by PV, WT, DG, MT, or FC. Each component of the micro-grid system is modelled separately based on its characteristic and constraints [7].

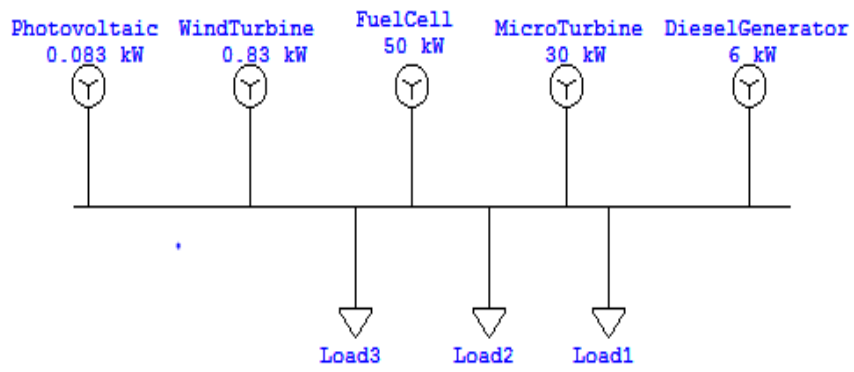

Fig. 1. Typical micro-grid.

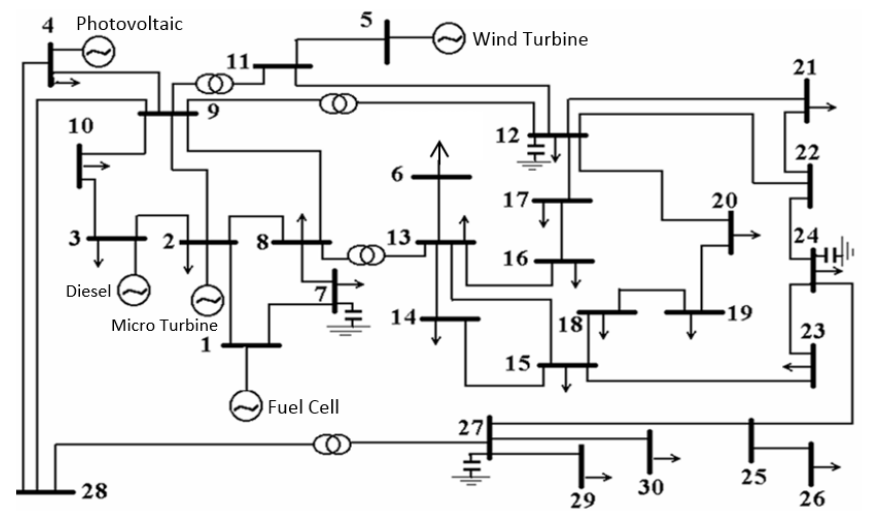

Fig. 2. Modified IEEE thirty-bus test [9].

\subsection{Optimization model}

To use the model of the plant, the power demand has to be defined by the load. Besides that, locally available energy information also has to be defined like solar irradiation data $\left(\mathrm{W} / \mathrm{m}^{2}\right)$, outside temperature $\left({ }^{\circ} \mathrm{C}\right)$, wind speed $(\mathrm{m} / \mathrm{s})$, as well as cost of fuels $(\$ /$ liter) for DG and natural gas price for supplying FC and MT (\$/kWh). It is important to know the technical and economic performance characteristics of supply options like rated power for PV, power curve for WT, and fuel consumption characteristics for DG, FC, and MT [7].

\subsection{Proposed objective function}

The major concern in the design of an electrical system that utilizes micro-grid sources is the accurate selection of output power that can economically satisfy the load demand, while minimizing the emission. Hence the proposed objective function is to minimize the operation cost $(\$ / \mathrm{h})$ and the emissions $(\mathrm{g} / \mathrm{h})$, subject to power balance constraints [7]. 


\section{A. Operating cost (OC)}

The cost function takes the form:

$$
C F(P)=C F\left(P_{F C}\right)+C F\left(P_{M T}\right)+C F\left(P_{D G}\right)
$$

where $C F(P)$ represents the operating costs in $\$ / \mathrm{h}, C F\left(P_{F C}\right)$ for the FC, $C F\left(P_{M T}\right)$ for the MT and $C F\left(P_{D G}\right)$ for the DG.

OC-Fuel Cell. The fuel cost for the fuel cell is calculated as follows [10]:

$$
C F\left(P_{F C}\right)=C_{n l} \frac{P_{F C}}{\eta}
$$

where $C_{n l}$ is the natural gas price to supply the fuel cell, $P_{F C}$ is the net electrical power, and $\eta$ is the cell efficiency.

OC-Micro Turbine. Micro turbine models are similar to those of fuel cells [10]-[12]. However, the parameters and curves are modified to properly describe the performance of a MT unit. The fuel cost for the micro turbine is calculated as follows:

$$
C F\left(P_{M T}\right)=C_{n l} \frac{P_{M T}}{\eta}
$$

where $C_{n l}$ is the natural gas price to supply the micro turbine, $P_{M T}$ is the net electrical power, and $\eta$ is the cell efficiency.

$O C$-Diesel Generator. The fuel cost of a power system can be expressed mainly as a function of its real power output and can be modelled by a quadratic polynomial [10], [13]. The total diesel fuel consumption rate (liter/h), $C F\left(P_{D G}\right)$ can be expressed as:

$$
C F\left(P_{D G}\right)=a+b P_{D G}+c P_{D G}^{2}
$$

where $a, b$, and $c$ are the coefficients of particular generator, $P_{D G}$ is the output power of the diesel generator in $(\mathrm{kW})$ assumed to be known. Typically, the constants $a, b$, and $c$ are given by the manufacturer. For example, diesel fuel consumption data of a $6-\mathrm{kW}$ diesel generator set (Cummins Power) model DNAC $50 \mathrm{~Hz}$ [10], [14] is available in liter/h at 1/4, 1/2, 3/4, and full loads. From the data sheet the parameters in (4) are: $a=0.4333, b=0.2333$, and $c=0.0074$.

Wind Turbine optimization. In the design of a wind turbine model, two important factors are considered; the availability of the wind and the power curve of the wind turbine itself. The available wind generator output, is a function of the wind velocity. In order to model the performance of the wind turbine, the power curve of the wind turbine must be obtained. The following is the model used to calculate the output power generated by the wind turbine generator [10], [15], [16]:

$$
P_{W T}=0, V_{a c}<V_{c i}, P_{W T}=a V_{a c}^{2}+b V_{a c}+c, V_{c i} \leq V_{a c}<V_{r}, P_{W T, r}=130, V_{r} \leq V_{a c}>V_{c o}
$$

where $P_{w t, r}, V_{c i}$, and $V_{c o}$ are the rated power, cut-in and cut-out wind speed, respectively. Furthermore, $V_{r}$ and $V_{a c}$ are the rated and actual wind speed, respectively. For modelling the performance of a wind turbine, the mathematical equation of the power curve of a wind turbine must be obtained. The parameters are as follows: $a=3.4 ; b=-12 ; c=9.2 ; P_{w t, r}=130$ watt; $V_{c i}=3.5 \mathrm{~m} / \mathrm{s} ; V_{c o}=18 \mathrm{~m} / \mathrm{s} ; V_{r}=$ $17.5 \mathrm{~m} / \mathrm{s}$.

Photovoltaic optimization. Photovoltaic generations are systems which convert the sunlight directly to electricity. The characteristics of the PV in operating conditions that differ from the standard condition $\left(1000 \mathrm{~W} / \mathrm{m}^{2}, 25^{\circ} \mathrm{C}\right.$ cell temperature), the influences of the solar irradiation and ambient temperature on PV characteristics are modelled. The effect of solar intensity is modelled by considering the power output of the module to be proportional to the irradiance [10], [17], [18]. The PV Modules are treated at Standard Test Condition (STC). The output power of the module can be calculated using equation (6): 


$$
P_{P V}=P_{S T C} \frac{G_{I N G}}{G_{S T C}}+k\left(T_{C}-T_{r}\right)
$$

where $P_{P V}$ is the output power of the module at irradiance $G_{I N G}, P_{S T C}$ is the module maximum power at STC, $G_{I N G}$ is incident irradiance, $G_{S T C}$ is irradiance at STC $1000 \mathrm{~W} / \mathrm{m}^{2}, k$ is temperature coefficient of power, $T_{C}$ is the cell temperature, $T_{r}$ is the reference temperature. SOLAREX MSX-83 modules are used in this research. Their output characteristics are: peak power $=83 \mathrm{~W}$, voltage at peak power $=17.1 \mathrm{~V}$, current at peak power $=4.84 \mathrm{~A}$, short circuit current $=5.27 \mathrm{~A}$, and open circuit voltage $=21.2 \mathrm{~V}$ at STC .

System Constraints. Power balance constraints: To meet the active power balance, an equality constraint is imposed [10]:

$$
P_{n e t}=P_{L}-P_{P V}-P_{W T}
$$

where $P_{L}$ is the total power demanded in $\mathrm{kW}, P_{P V}$ the output power of the photovoltaic cell in $\mathrm{kW}, P_{W T}$ the output power of the wind turbine in $\mathrm{kW}$.

Generation capacity constraints: For stable operation, real power output of each generator is restricted by lower and upper limits as follows:

$$
P_{i}^{\min } \leq P_{i} \leq P_{i}^{\max } \quad \forall_{i}=1,2, \cdots, N
$$

where $P_{i}^{\min }$ is the minimum operating power of unit $i$ and $P_{i}^{\max }$ is the maximum operating power of unit $i$. Unit $i$ is $\mathrm{FC}, \mathrm{MT}$, and DG.

\section{B. Emission level}

The atmospheric pollutants such as sulphur oxides $\mathrm{SO}_{2}$, carbon oxides $\mathrm{CO}_{2}$, and nitrogen oxides $\mathrm{NOx}$ caused by fossil-fueled thermal units can be modeled separately. The total $\mathrm{g} / \mathrm{h}$ emission of these pollutants can be expressed as [10], [21]:

$$
E(P)=\left(\alpha_{F C}+\beta_{F C}+\gamma_{F C}\right) P_{F C}+\left(\alpha_{M T}+\beta_{M T}+\gamma_{M T}\right) P_{M T}+\left(\alpha_{D G}+\beta_{D G}+\gamma_{D G}\right) P_{D G}
$$

where $\alpha_{F C}, \alpha_{M T}$, and $\alpha_{D G}$ are nonnegative coefficients of $\mathrm{SO}_{2} ; \beta_{F C}, \beta_{M T}$, and $\beta_{D G}$ are nonnegative coefficients of $\mathrm{CO}_{2} ; \gamma_{F C}, \gamma_{M T}$, and $\gamma_{D G}$ are nonnegative coefficients of NOx.

For the emission model introduced in [20] and [21], we propose to evaluate the parameters $\alpha_{F C}, \alpha_{M T}$, $\alpha_{D G}, \beta_{F C}, \beta_{M T}, \beta_{D G}, \gamma_{F C}, \gamma_{M T}$, and $\gamma_{D G}$ using the data available in [19]. Thus, the emission per day for the FC, MT, and DG is estimated, and the characteristics of each generator will be detached accordingly.

\section{Optimal power flow}

For a balanced three-phase system, power-flow equations are given in [22]:

$$
P_{i}=V_{i} \sum_{i=1}^{N} Y_{i j} V_{j} \cos \left(\delta_{i}-\delta_{j}-\theta_{i j}\right), Q_{i}=V_{i} \sum_{i=1}^{N} Y_{i j} V_{j} \sin \left(\delta_{i}-\delta_{j}-\theta_{i j}\right), I_{i j}=\left|V_{i} \cdot e^{i \delta_{i}}-V_{j} \cdot e^{i \delta_{j}}\right|
$$

where $i=1, \ldots, N$. $N$ is the number of buses. In equation (10), $Y_{i j}$ and $\theta_{i j}$ are the admittances magnitude and phase, $Y_{i i}$ are the self-admittances, $Y_{i j}(i \neq j)$ are the cross admittances, and $I_{i j}$ are the line currents (magnitude).

\section{Implementation of the Algorithm}

The key characteristics of the proposed algorithm are as follows [7]:

- Power output of WT is calculated according to the relation between the wind speed and the output power

- Power output of PV is calculated according to the effect of the temperature and the solar radiation that are different from the standard test condition.

- It is assumed that the WT and PV deliver free cost power in terms of running as well being emission 
free. Furthermore, their output power is treated as a negative load, determine the different between the actual load and WT and PV output power. The net load is calculated if the output from PV and WT is smaller than the total load demand.

- Choose serving the load by other sources (FC or MT or DG) according to the objective functions, where FC is the cheapest source and DG is the most expensive one.

\section{Multi-Objective Genetic Algorithm}

The simplest and most obvious approach to multi-objective optimization is to combine the objectives into one aggregating function, and to treat the problem like a single objective optimization problem. Therefore, it is commonly used because of its simplicity and computational efficiency. The weighted sum approach combines objectives using weights [7]. It can be expressed as:

$$
\text { fitness }=w_{1} C F(P)+w_{2} E(P)
$$

In this research the weighting factor was selected to 0.5 . Therefore, the priority of operation cost and emissions is balanced. This multi-objective can easily handle mixed- integer variables, non-smooth functions, and logical constraints [8], as shown in the following flow chart in Fig. 3.

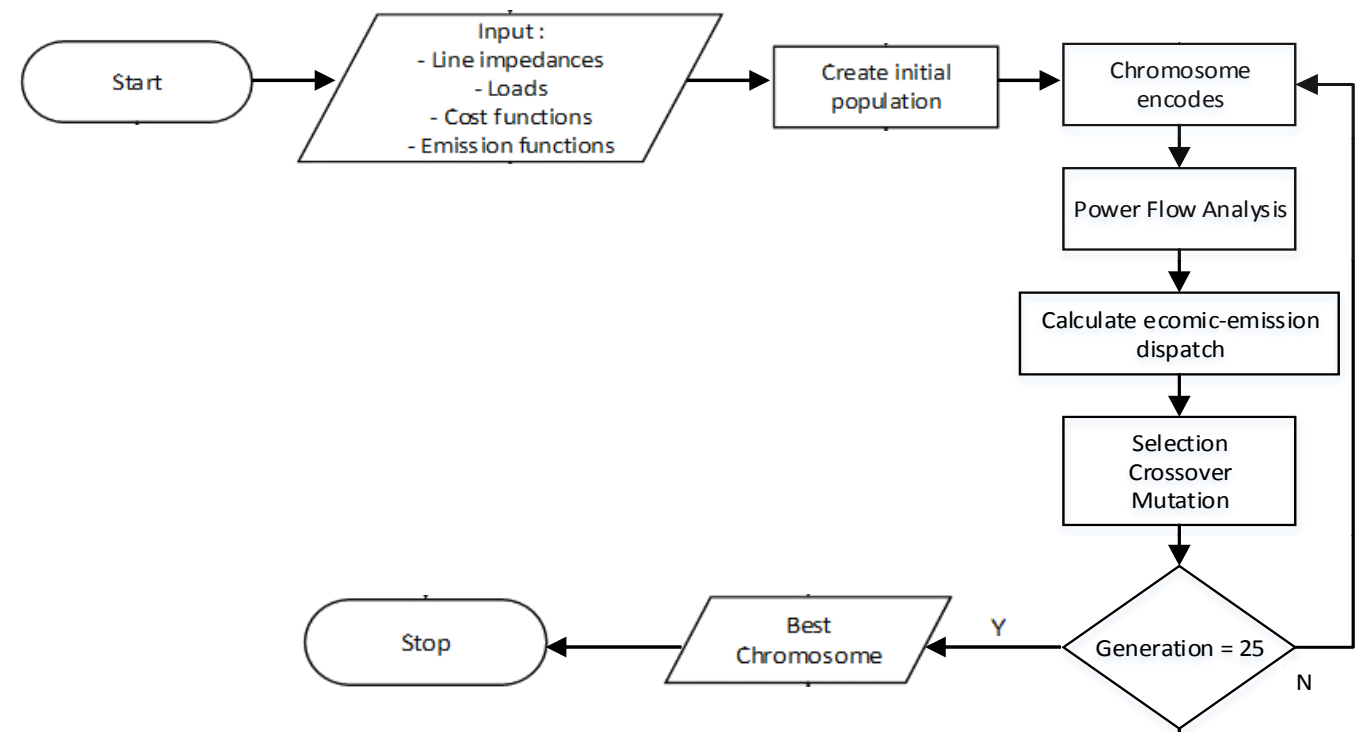

Fig. 3. Flow chart of multi-objective genetic algorithm.

\section{Results and Discussion}

The test system is shown in Fig. 2. The optimization model is applied to the system with varying load demand from $17 \mathrm{~kW}$ to $80 \mathrm{~kW}$. The available power from PV and WT are used first. The best results of the cost and emission functions considering the OPF are given in Table 1. The convergence of operation cost and emission objective function (fitness) for both approaches is shown in Fig. 4. Table 1 confirms that when the load demand is low, the best choice in terms of cost and emission is to use the output power from FC. The second best choice is the use of the MT. When the load is high, all the generators are used to serve the load. It also confirms that the solution is suitable and can be used in real power system because the voltage magnitude and angle, and the reactive power are considered including the losses.

Table 2 shows different results of the cost savings and emission reductions in micro-grid without considering OPF. It shows that the results are better than optimization considering the OPF because limitations of the system variables are not considered. 
Table 1. Objective function considering OPF

\begin{tabular}{|c|c|c|c|c|c|c|c|}
\hline $\begin{array}{c}\text { Total Load } \\
(\mathrm{kW} / \mathrm{h})\end{array}$ & $\begin{array}{l}\text { PV Power } \\
\text { (kW/h) }\end{array}$ & $\begin{array}{c}\text { WT Power } \\
(\mathrm{kW} / \mathrm{h})\end{array}$ & $\begin{array}{l}\text { FC Power } \\
\text { (kW/h) }\end{array}$ & $\begin{array}{l}\text { MT Power } \\
(\mathrm{kW} / \mathrm{h})\end{array}$ & $\begin{array}{c}\text { DG Power } \\
\text { (kW/h) }\end{array}$ & $\begin{array}{c}\text { Total Emissions } \\
(\mathrm{g} / \mathrm{h})\end{array}$ & Total Costs $(\$ / \mathrm{h})$ \\
\hline 17.592 & 0.342 & 2.971 & 12.698 & 1.568 & 0.012 & 17.645 & 3.192187345 \\
\hline 34.166 & 0.342 & 2.971 & 30.39 & 0.261 & 0.202 & 39.171 & 4.666322832 \\
\hline 54.643 & 0.342 & 2.971 & 41.613 & 9.457 & 0.26 & 71.856 & 10.08247088 \\
\hline 77.17 & 0.342 & 2.971 & 44.785 & 28.857 & 0.214 & 113.95 & 15.73494531 \\
\hline
\end{tabular}

Table 2. Objective function without considering OPF

\begin{tabular}{|c|c|c|c|c|c|c|c|}
\hline $\begin{array}{c}\text { Total Load } \\
\text { (kW/h) }\end{array}$ & $\begin{array}{l}\text { PV Power } \\
\text { (kW/h) }\end{array}$ & $\begin{array}{l}\text { WT Power } \\
\text { (kW/h) }\end{array}$ & $\begin{array}{l}\text { FC Power } \\
\text { (kW/h) }\end{array}$ & $\begin{array}{l}\text { MT Power } \\
\text { (kW/h) }\end{array}$ & $\begin{array}{c}\text { DG Power } \\
(\mathrm{kW} / \mathrm{h})\end{array}$ & $\begin{array}{l}\text { Total Emissions } \\
(\mathrm{g} / \mathrm{h})\end{array}$ & Total Costs $(\$ / \mathrm{h})$ \\
\hline 17.592 & 0.342 & 2.971 & 14.001 & 0.371 & 0.016 & 16.744 & 2.428579204 \\
\hline 34.166 & 0.342 & 2.971 & 30.781 & 0.025 & 0.055 & 35.635 & 4.436633186 \\
\hline 54.643 & 0.342 & 2.971 & 49.764 & 1.648 & 0.009 & 59.016 & 8.87800469 \\
\hline 77.17 & 0.342 & 2.971 & 48.468 & 25.434 & 0.101 & 108.388 & 15.39362973 \\
\hline
\end{tabular}

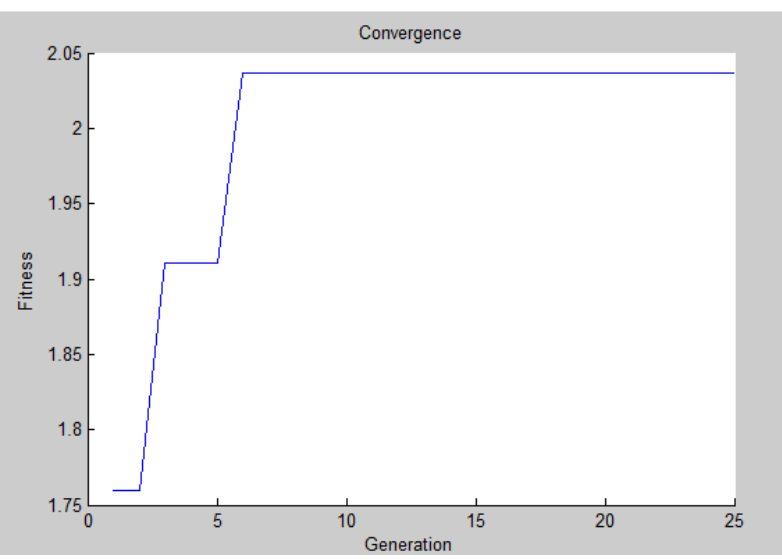

Fig. 4. Convergence of objective functions.

\section{Conclusions}

This research suggests an algorithm to compute the optimal energy management in islanded micro-grid. This optimization minimizes the operational cost and the emissions while constraining it to meet customer demand and safety of the micro-grid system. This method which integrates Optimal Power Flow with Economic-Emission Dispatch successfully determines optimal solution close to real condition as well as safety of the system.

\section{References}

[1] Wang JH, Tai NL, Song K. Penetration level permission of for DG in distributed network considering relay protection. Proceedings of the CSEE, 2010; 30(22):37-43.

[2] Yu K, Cao Y, Chen X. Dynamic probability power flow of district grid containing distributed generation. Proceedings of the CSEE, 2011; 31(1):20-25.

[3] Zhong Q, et al. Environmental and economic dispatch model for smart microgrid based on shuffled frog leap algorithm optimized by random Nelder mead. Przegląd Elektrotechniczny, R. 89 NR 3b/2013.

[4] Zhao B, Guo CX, Cao YJ. A multiagent-based particle swarm optimization approach for optimal reactive power dispatch. IEEE Transactions on Power Systems, May 2005; 20(2):1070-1078.

[5] Cai HR,. Chung CY, Wong KP. Application of differential evolution algorithm for transient stability constrained optimal power flow. IEEE Transactions on Power Systems, May 2007; 23(2):719-728.

[6] Su C, Chen Z. An optimal power flow (OPF) method with improved power system stability. In: Proc. Universities Power Engineering Conference, 2010 45th International. IEEE, 2010.

[7] Mohamed FA, Koivo HN. Environmental/economic power dispatch of microgrid using multiobjective genetic algorithms. Presented at: International Renewable Energy Congress, Sousse, Tunisia, November 5-7, 2010. 
[8] E. Grzegorz, W. Kurek, M.A. Brdys. Grid implementation of a parallel multiobjective genetic algorithm for optimized allocation of chlorination stations in drinking water distribution systems: Chojnice case study. IEEE Transactions on Systems, Man, and Cybernetics, Part C: Applications and Reviews, 2008; 38(4):497-509.

[9] Alwash, Shamam F. Online monitoring, evaluation and improvement of steady state voltage stability for electric power systems using artificial neural networks techniques. Journal of Babylon University/Pure and Applied Sciences, 2011; 19(1).

[10] Mohamed FA, Koivo HN. Modelling and environmental/economic power dispatch of microgrid using multi objective genetic algorithm optimization. Fundamental and Advanced Topics in Wind Power, R. Carriveau Ed., 2011,

[11] S. Campanari, E. Macchi. Technical and tariff scenarios effect on microturbine trigenerative applications. Journal of Engineering for Gas turbines and Power, July 2004; 126:581-589.

[12] S. Campanari, L. Boncompagni, E. Macchi. Microturbines and trigeneration: Optimization strategies and multiple engine configuration effects. Journal of Engineering for Gas turbines and Power, January 2004; 126:92-101,.

[13] A.J. Wood, B.F. Wollenberg. Power Generation, Operation and Control. John Wiley \& Sons, Ltd, New York, 1996.

[14] [Online]. Available: http://www.cumminspower.com/commercial1/diesel/s-1215.pdf. Technical Report.

[15] R. Chedid, H. Akiki, S. Rahman. A decision support technique for the design of hybrid solar-wind power systems. IEEE Transaction on Energy Conversion, March 1998; 13(1):76-83.

[16] M.K.C. Marwali, H. Ma, S.M. Shahidehpour, K.H. Abdul-Rahman. Short term generation schcduling in photovoltaic-utility grid with battery storage. IEEE Transaction on Power System, August 1998; 13(3):1057-1062.

[17] E.S. Gavanidou, A.G. Bakirtzis. Design of a stand alone system with renewable energy sources using trade off methods. IEEE Transaction on Energy Conversion, 1992; 7(1):42-48.

[18] F. Lasnier, T.G. Ang. Photovoltaic Engineering Handbook. IOP Publishing Ltd, Adam Hilger, New York; 1990.

[19] Morgantown W. Emission Rates for New DG Technologies. The Regulatory Assistance Project. [Online] Available: http://www.raponline.org ProjDocs/DREmsRul/Collfile/DGEmissionsMay2001.pdf

[20] J.H. Talaq, F. El-Hawary, M.E. El-Hawary. A summary of environmental/economic dispatch algorithms. IEEE Transactions on Power Syst, Aug. 1994; 9(4):1508-1516.

[21] M.A. Abido. Enverionmental/economic power dispatch using multiobjective evolutionary algorithms. IEEE Transactions on Power Syst, November 2003; 18(4):1529-1537.

[22] Levron Y, J.M. Guerrero, Y. Beck. Optimal power flow in microgrids with energy storage. IEEE Transactions on Power Systems, 2013; 28(3):3226-3234. 